\title{
Bandstructure of Interdiffused InGaN/GaN Quantum Well
}

\author{
Elaine M. T. Cheung, Michael C. Y. Chan, and E. Herbert Li \\ Department of Electrical and Electronic Engineering, University of \\ Hong Kong, Pokfulam Road, Hong Kong
}

\begin{abstract}
Quantum well composition intermixing is a thermal induced interdiffusion of the constituent atoms through the heterointerface. The intermixed structures created by both impurity induced and impurity-free vacancy promoted processes have recently attracted high attention. In recent years, blue green LED and laser of III-nitride semiconductors have attracted a large amount of interest. This is mainly due to its large bandgap range from $1.89 \mathrm{eV}$ (wurtzite $\mathrm{InN}$ ) to $3.44 \mathrm{eV}$ (wurtzite $\mathrm{GaN}$ ). InGaN/GaN single quantum well structures have been used to achieve high lumens blue and green light emitting diodes. In this paper, we will present the band structure of strained InGaN/GaN single quantum well under the influence of interdiffusion. Band structure is a fundamental aspect in determining the electronic and optical properties of the materials such as optical gain, refractive index, absorption, etc.
\end{abstract}

Keywords: bandstructure, quantum well, interdiffusion, wurtzite III-nitride, InGaN/GaN, Fick's law, in-plane strain

\section{INTRODUCTION}

Short wavelength semiconductor lasers are very important for high-density optical storage applications. Widebandgap semiconductors including GaN, AlN, InN and their ternary compounds have been studied for the realization of semiconductor blue-green laser. The demonstration of high-brightness blue-green light-emitting diodes from the wurtzite $\mathrm{GaN}$ semiconductor has stimulated a lot of research on the fabrication of blue-green laser diodes using nitride-based semiconductors [1]. InGaN/GaN single-quantum-well structures have been used to achieve high-power blue and green lightemitting diodes [2]. Room temperature pulsed lasing of a strained InGaN/GaN multiquantum-well laser diode has recently been demonstrated [3].

The nature crystal structure of most of the group III nitrides is wurtzite. Strain is also present in most of group III nitrides because of the lack of substrate materials with a matched lattice constant and thermal expansion coefficient. Fundamental studies of the effects of strain on wurtzite band structure play an important role in understanding the electronic and optical properties of GaN-based optoelectronic materials and devices. In below sections, we will study the effect of interdiffusion of group III atom (In) in the $\mathrm{QW}$ of $\mathrm{WZ}-\mathrm{InGaN} / \mathrm{GaN}$ band structure.

\section{THEORETICAL MODEL}

This paper presents a theoretical study of the effects of interdiffusion in a InGaN/GaN single QW structure. The effects of interdiffusion on the strains, the splitting of the heavy-hole (HH), light-hole (LH), and the crystal-field split-hole $(\mathrm{CH})$ subbands and their dispersion, are calculated theoretically based on the Hamiltonian derived using the multi-band k.p model. The Hamiltonian is actually a set of coupled linear differential equations for the envelope functions, which can also be solved using the finite-difference approximation and the Hamiltonian is derived by S. L. Chuang and Chang using the k.p methed [4]. 
The effective Hamiltonian we used in the calculation of WZ-InGaN/GaN QW band structure was:

$$
\mathrm{H}_{6 \times 6}^{\mathrm{v}}(\mathrm{k})=\left[\begin{array}{cc}
\mathrm{H}_{3 \times 3}^{\mathrm{U}}(\mathrm{k}) & 0 \\
0 & \mathrm{H}_{3 \times 3}^{\mathrm{L}}(\mathrm{k})
\end{array}\right]
$$

where $\mathrm{H}^{\mathrm{U}}$ and $\mathrm{H}^{\mathrm{L}}$ are $3 \times 3$ matrices,

$$
\begin{aligned}
\mathrm{H}^{\mathrm{U}} & =\left[\begin{array}{ccc}
\mathrm{F} & \mathrm{K}_{\mathrm{t}} & -\mathrm{iH}_{\mathrm{t}} \\
\mathrm{K}_{\mathrm{t}} & \mathrm{G} & \Delta-\mathrm{iH}_{\mathrm{t}} \\
\mathrm{iH}_{\mathrm{t}} & \Delta+\mathrm{iH}_{\mathrm{t}} & \lambda
\end{array}\right] \\
\mathrm{H}^{\mathrm{L}} & =\left[\begin{array}{ccc}
\mathrm{F} & \mathrm{K}_{\mathrm{t}} & \mathrm{iH}_{\mathrm{t}} \\
\mathrm{K}_{\mathrm{t}} & \mathrm{G} & \Delta+\mathrm{iH}_{\mathrm{t}} \\
-\mathrm{iH}_{\mathrm{t}} & \Delta-\mathrm{iH}_{\mathrm{t}} & \lambda
\end{array}\right]
\end{aligned}
$$

Note that these relations hold: $\mathrm{H}^{\mathrm{U}}=\left(\mathrm{H}^{\mathrm{L}}\right)^{*}=\left(\mathrm{H}^{\mathrm{L}}\right)^{\mathrm{t}}$, where the superscript '*' means complex conjugate and ' $\mathrm{t}$ ' means transpose of the matrix elements, where

$$
\begin{aligned}
& \mathrm{F}=\Delta_{1}+\Delta_{2}+\lambda+\theta \\
& \mathrm{G}=\Delta_{1}-\Delta_{2}+\lambda+\theta \\
& \lambda=\lambda_{\mathrm{k}}+\lambda_{\epsilon} \\
& \lambda_{\mathrm{k}}=\frac{\hbar^{2}}{2 \mathrm{~m}_{\mathrm{o}}}\left(\mathrm{A}_{1} \mathrm{k}_{\mathrm{z}}^{2}+\mathrm{A}_{2} \mathrm{k}_{\mathrm{t}}^{2}\right) \\
& \lambda_{\epsilon}=\mathrm{D}_{1} \epsilon_{\mathrm{zz}}+\mathrm{D}_{2}\left(\epsilon_{\mathrm{xx}}+\epsilon_{\mathrm{yy}}\right) \\
& \theta=\theta_{\mathrm{k}}+\theta_{\epsilon} \\
& \theta_{\mathrm{k}}=\frac{\hbar^{2}}{2 \mathrm{~m}_{\mathrm{o}}}\left(\mathrm{A}_{3} \mathrm{k}_{\mathrm{z}}^{2}+\mathrm{A}_{4} \mathrm{k}_{\mathrm{t}}^{2}\right) \\
& \theta_{\epsilon}=\mathrm{D}_{3} \epsilon_{\mathrm{zz}}+\mathrm{D}_{4}\left(\epsilon_{\mathrm{xx}}+\epsilon_{\mathrm{yy}}\right) \\
& \mathrm{K}_{\mathrm{t}}=\frac{\hbar^{2}}{2 \mathrm{~m}_{\mathrm{o}}} \mathrm{A}_{5} \mathrm{k}_{\mathrm{t}}^{2} \\
& \mathrm{H}_{\mathrm{t}}=\frac{\hbar^{2}}{2 \mathrm{~m}_{\mathrm{o}}} \mathrm{A}_{6} \mathrm{k}_{\mathrm{t}} \mathrm{k}_{\mathrm{z}} \\
& \Delta=\sqrt{2 \Delta_{3}}
\end{aligned}
$$

where $k_{t}=\sqrt{k_{x}^{2}+k_{y}^{2}}$ is the magnitude of the wavevector in the $\mathrm{k}_{\mathrm{x}}-\mathrm{k}_{\mathrm{y}}$ plane.

In the above Hamiltonian, we have assumed that the strain tensor is diagonal, i.e. $\varepsilon_{i, j}=0$ for $i$ not equal to $\mathrm{j}$. The strained exists can be calculated by

$$
\begin{aligned}
& \epsilon_{x x}=\epsilon_{y y}=\frac{a_{0}-a}{a} \\
& \epsilon_{z z}=\frac{-2 c_{13}}{c_{33}} \epsilon_{x x} \\
& \epsilon_{x y}=\epsilon_{y z}=\epsilon_{z x}=0
\end{aligned}
$$

where $a_{0}$ and $a$ are the lattice constants of the substrate and the well layer material respectively, $C_{i j}$ are the stiffness constants. The bases for the block diagonalized Hamiltonian are defined as 


$$
\begin{aligned}
& \left|1>=\alpha^{*}\right| Y \uparrow>+\alpha \mid Y_{1-1} \downarrow> \\
& |2>=\beta| Y_{1-1} \uparrow>+\beta^{*} \mid Y_{11} \downarrow> \\
& \left|3>=\beta^{*}\right| Y_{10} \uparrow>+\beta \mid Y_{10} \downarrow> \\
& \left|4>=\alpha^{*}\right| Y_{11} \uparrow>-\alpha \mid Y_{1-1} \downarrow> \\
& |5>=\beta| Y_{1-1} \uparrow>-\beta^{*} \mid Y_{11} \downarrow> \\
& \left|6>=-\beta^{*}\right| Y_{10} \uparrow>+\beta \mid Y_{10} \downarrow> \\
& Y_{11}=\frac{-1}{\sqrt{2}} \mid X+i Y> \\
& Y_{10}=\mid Z> \\
& Y_{1-1}=\frac{1}{\sqrt{2}} \mid X-i Y> \\
& \alpha=\frac{1}{\sqrt{2}} e^{i\left(\frac{3 \pi}{4}+\frac{3 \phi}{2}\right)} \\
& \beta=\frac{1}{\sqrt{2}} e^{i\left(\frac{\pi}{4}+\frac{\phi}{2}\right)} \\
& \phi=\tan ^{-1}\left(k_{x} / k_{y}\right)
\end{aligned}
$$

where $\phi$ is the azimuthal angle in the $k_{x}-k_{y}$ plane and covers a range between 0 and $2 \pi$.

It should be pointed out that under the cubic approximation, the following relations hold among the parameters $A_{i}$, $D_{i}$ and $\Delta_{i}$ :

$$
\begin{aligned}
& A_{1}-A_{2}=-A_{3}=2 A_{4} \\
& A_{3}+4 A_{5}=\sqrt{2} A_{6} \\
& D_{1}-D_{2}=-D_{3}=2 D_{4} \\
& \Delta_{2}=\Delta_{3}
\end{aligned}
$$

Typically, five band structure parameters such as $\mathrm{A}_{1}, \mathrm{~A}_{2}, \mathrm{~A}_{5}, \Delta_{1}$ and $\Delta_{2}$, plus two deformation potentials $\mathrm{D}_{1}$ and $\mathrm{D}_{2}$, are necessary for the calculation of the valence band structures. The other parameters can be obtained from the above relations.

QW composition intermixing is a thermal induced interdiffusion of the constituent atoms through the heterointerface. The interdiffused structures created by both impurity induced and impurity-free vacancy promoted processes have recently attracted high attention [5-7]. The interdiffusion mechanism can be a single-phase diffusion for two constituent atoms or it can be two or multiple phases and/or for multiple species. In InGaN/GaN QW structures only the interdiffusion of group-III atoms occurs, i.e. In and Ga atoms, since there is no $\mathrm{N}$ concentration gradient across the interface. The diffusion of group III atoms in the QW structure is usually described by the Fick's law with constant diffusion coefficients in both the well and barrier layers. The composition profile after interdiffusion is characterized by a diffusion length $L_{d}$, which is defined as $L_{d}=\sqrt{ }(D t)$, where $D$ is the diffusion coefficient and $t$ is the annealing time of thermal processing. The In mole fraction across the InGaN/GaN QW structure after interdiffusion is given by:

$$
x_{\text {In }}(z)=\frac{x_{0}}{2}\left[\operatorname{erf}\left(\frac{L_{w}+2 z}{4 L_{d}}\right)+\operatorname{erf}\left(\frac{L_{w}-2 z}{4 L_{d}}\right)\right]
$$


where $\mathrm{z}$ denotes the co-ordinate along the crystal growth direction, $\mathrm{L}_{\mathrm{w}}$ is the as-grown well width, $\mathrm{x}_{0}$ is the as-grown In mole fraction.

\section{RESULTS AND DISCUSSION}

The in-plane valence band dispersion of InGaN/GaN SQW was calculated using the parameters of GaN, InN shown in Table 1. Alloy properties of $\operatorname{In}_{\mathrm{x}} \mathrm{Ga}_{1-\mathrm{x}} \mathrm{N}$ are obtained by linear interpolation except for the gap energy in which a bowing parameter of $b=1.75 \mathrm{eV}$ for InGaN/GaN respectively are taken. The partition ratio for the band edge discontinuity at the heterojunction for the valence and conduction bands is assumed to be 33:67 for both QW systems.

Table1: Material Parameters used in calculating the band structure of InGaN/GaN QW.

\begin{tabular}{|c|c|c|}
\hline Parameters & $\mathrm{GaN}$ & $\operatorname{InN}$ \\
\hline $\mathrm{a}(\AA)$ & 3.189878 & 3.544 \\
\hline $\mathrm{E}_{\mathrm{g}}(\mathrm{eV})$ at $300 \mathrm{~K}$ & 3.44 & 1.89 \\
\hline$\Delta_{1}=\Delta_{\mathrm{cr}}(\mathrm{meV})$ & 10 & 27.8 \\
\hline$\Delta_{2}=\Delta_{3}(\mathrm{meV})$ & 5.170204 & 3.9 \\
\hline $\mathrm{m}_{\mathrm{e}}^{\mathrm{z}}\left(\mathrm{m}_{\mathrm{o}}\right)$ & 0.2 & 0.11 \\
\hline $\mathrm{m}_{\mathrm{e}}^{\mathrm{t}}\left(\mathrm{m}_{\mathrm{o}}\right)$ & 0.18 & 0.1 \\
\hline$A_{1}$ & -6.56 & -9.28 \\
\hline $\mathrm{A}_{2}$ & -0.91 & -0.6 \\
\hline$A_{3}$ & 5.65 & 8.68 \\
\hline$\overline{A_{4}}$ & -2.83 & -4.34 \\
\hline $\mathrm{A}_{5}$ & -3.13 & -4.32 \\
\hline $\mathrm{A}_{6}$ & -4.86 & -6.08 \\
\hline$\overline{a_{c}(e V)}$ & -11.8 & -1.2 \\
\hline $\mathrm{D}_{1}(\mathrm{eV})$ & 0.7 & 0.35 \\
\hline $\mathrm{D}_{2}(\mathrm{eV})$ & 2.1 & 1.05 \\
\hline $\mathrm{D}_{3}(\mathrm{eV})$ & 1.4 & 1.31768 \\
\hline $\mathrm{D}_{4}(\mathrm{eV})$ & -0.7 & -0.7412 \\
\hline$C_{13}\left(10^{11}\right.$ dyn $\left.\mathrm{cm}^{-2}\right)$ & 10 & 9.4 \\
\hline$C_{33}\left(10^{11}\right.$ dyn $\left.\mathrm{cm}^{-2}\right)$ & 39.2 & 20 \\
\hline
\end{tabular}

The strain of InGaN/GaN QW is compressive in nature. The strain exists will push the valence subbands downwards. Therefore, it was shown on Fig. 1 \& Fig. 2 that the valence band dispersion of InGaN/GaN shifts downwards due to larger strain associated in InGaN/GaN QW structure. With larger In mole fraction as shown in Fig. $1 \&$ Fig. 2 with In mole fraction of 0.09 and 0.16 respectively, the strain associated increase with In mole fraction, then the valence band structure shifts further downward. The top two valence subbands, HH1 and LH1, shifts downwards by almost the same amount at the $\Gamma$ point. The comparison of experimental transition energy and theoretical values are shown in Table 2 (we assumed the exciton level to be $28 \mathrm{meV}$ ).

Table2: Comparison of experimental results with our works at room temperature

\begin{tabular}{|l|l|l|}
\hline QW & $\mathrm{In}_{0.16} \mathrm{Ga}_{0.84} \mathrm{~N} / \mathrm{GaN}$ & $\mathrm{In}_{0.09} \mathrm{Ga}_{0.91} \mathrm{~N} / \mathrm{GaN}$ \\
\hline Expt. & $\mathrm{PL}$ & $\mathrm{PL}$ \\
\hline Ref. & {$[8]$} & {$[9]$} \\
\hline $\mathrm{L}_{\mathrm{w}}(\AA)$ & 50 & 80 \\
\hline Expt. Results (eV) & 3.032 & 3.1633 \\
\hline Our Works (eV) & 3.028 & 3.1712 \\
\hline Error (meV) & -4 & 7.9 \\
\hline
\end{tabular}




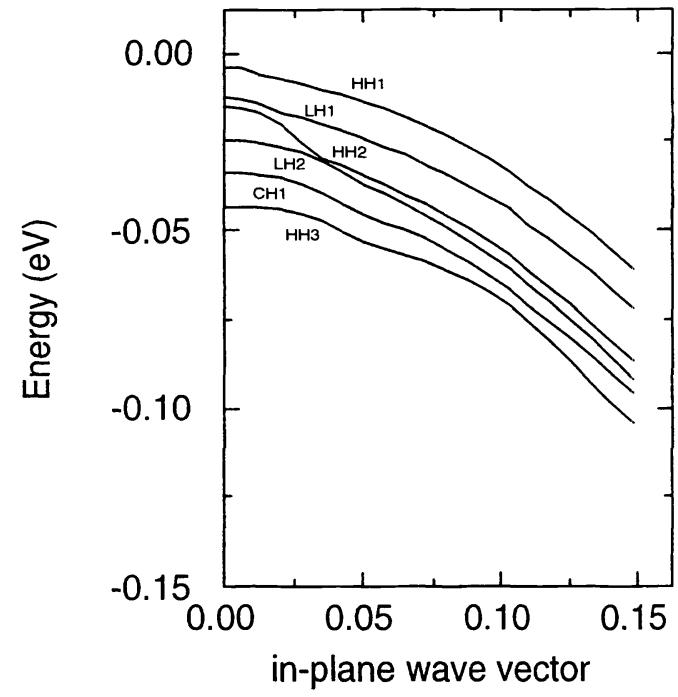

Fig. 1 The valence band structure of $\mathrm{In}_{0.16} \mathrm{Ga}_{0.84} \mathrm{~N} / \mathrm{GaN}$ with $\mathrm{L}_{\mathrm{w}}=50 \AA$ and $\mathrm{L}_{\mathrm{d}}=0$.

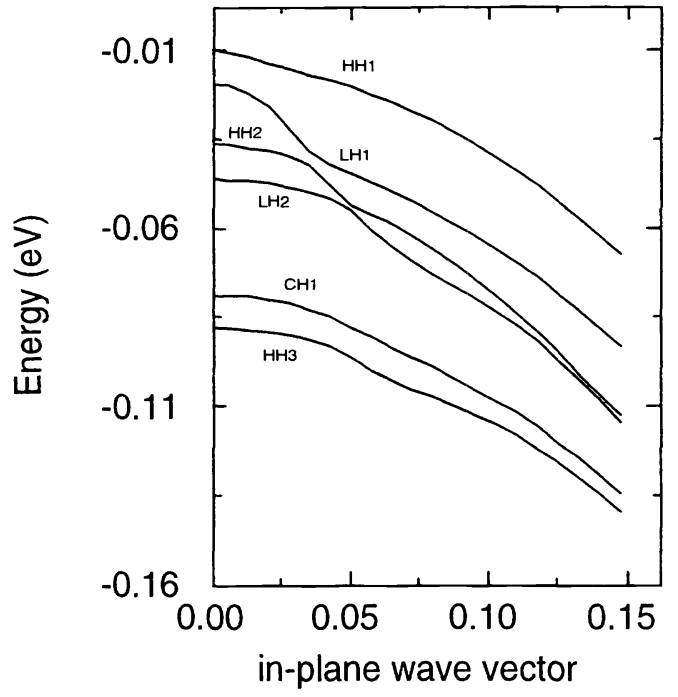

Fig 2 The valence band structure of $\mathrm{In}_{0.09} \mathrm{Ga}_{0.91} \mathrm{~N} / \mathrm{GaN}$ with $\mathrm{L}_{\mathrm{w}}=80 \AA$ and $\mathrm{L}_{\mathrm{d}}=0$.

For as-grown well with $\mathrm{L}_{\mathrm{w}}=50 \AA$ and $\mathrm{x}=0.16$ (Fig. 1), it was found that there is a strong coupling of LH1 and HH2 at region $k_{t}$ greater than $0.03 \AA^{-1}$ and coupling of $H H 2$ and $L H 2$ in region where $k_{t}$ greater than $0.05 \AA^{-1}$. It was also found that $\mathrm{HH} 1$ was quite parabolic in shape. Besides, higher order subbands and subbands in regions where $\mathrm{k}_{\mathrm{t}}$ is large enough are parabolic in shape.

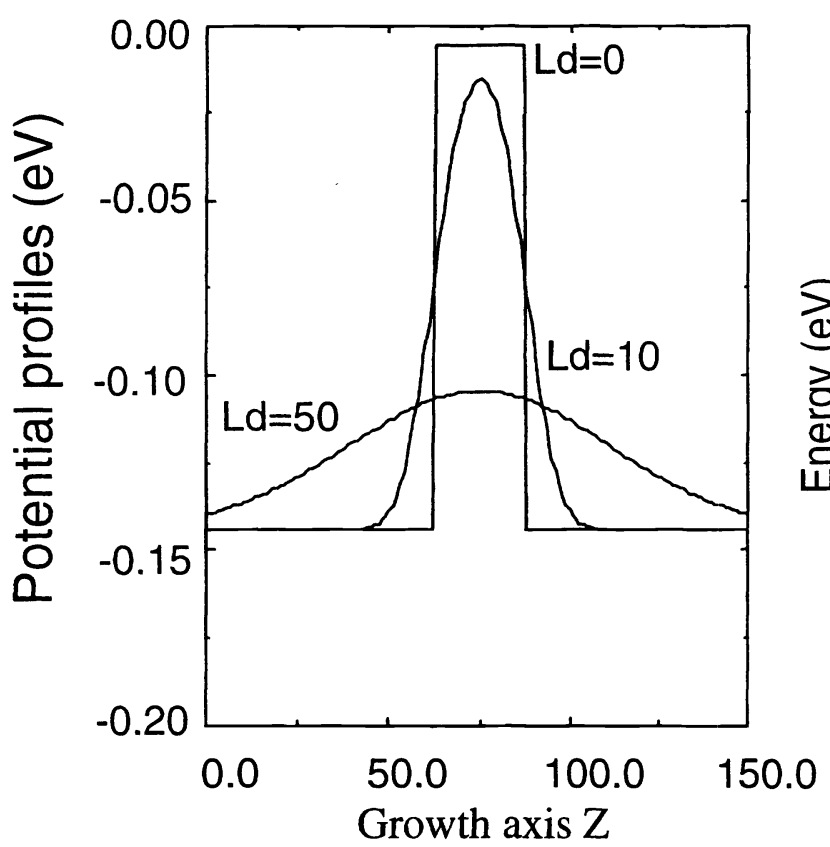

Fig. 3 The potential profile of $\operatorname{In}_{0.16} \mathrm{Ga}_{0.84} \mathrm{~N} / \mathrm{GaN}$ with $\mathrm{L}_{\mathrm{w}}=50 \AA$ and $\mathrm{L}_{\mathrm{d}}=0$.

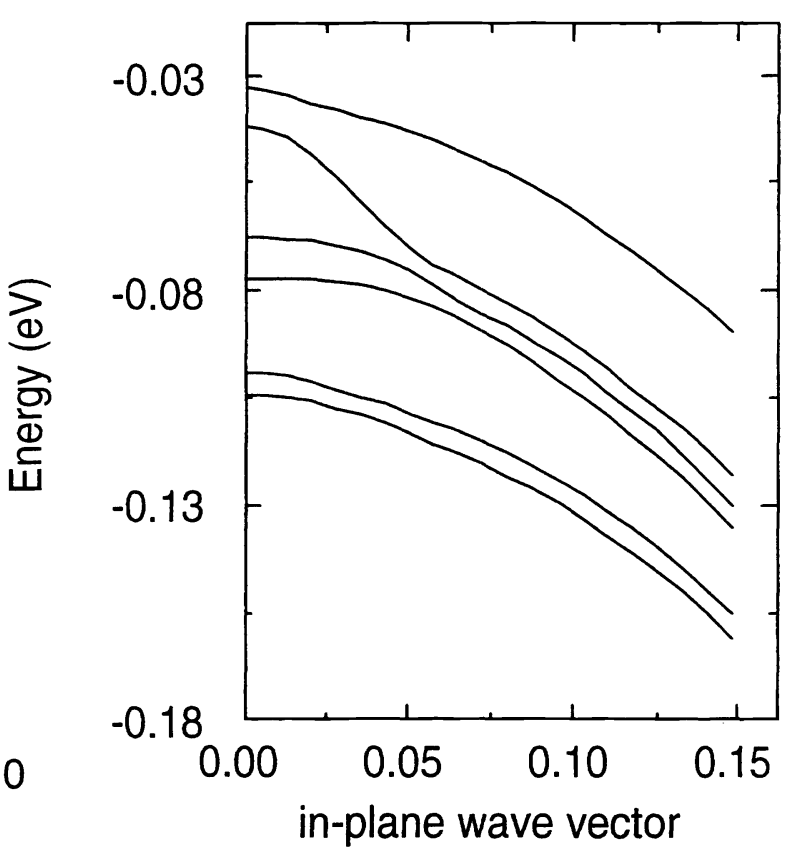

Fig. 4 The valence band structure of $\mathrm{In}_{0.16} \mathrm{Ga}_{0.84} \mathrm{~N} / \mathrm{GaN}$ with $\mathrm{L}_{\mathrm{w}}=50 \AA$ and $\mathrm{L}_{\mathrm{d}}=10 \AA$ 


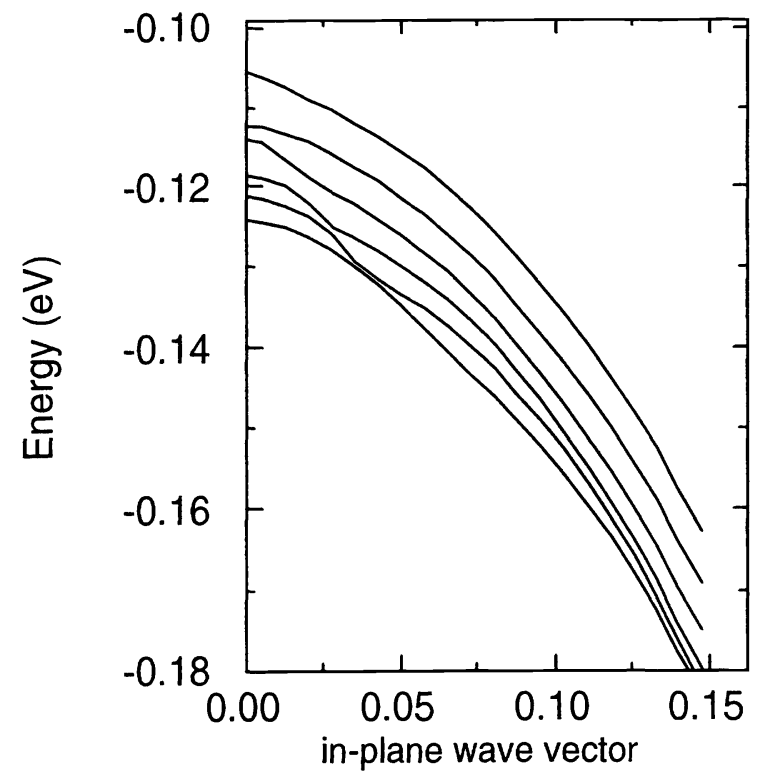

Fig. 5 The valence band structure of $\mathrm{In}_{0.16} \mathrm{Ga}_{0.84} \mathrm{~N} / \mathrm{GaN}$ with $\mathrm{L}_{\mathrm{w}}=50 \AA$ and $\mathrm{L}_{\mathrm{d}}=50 \AA$

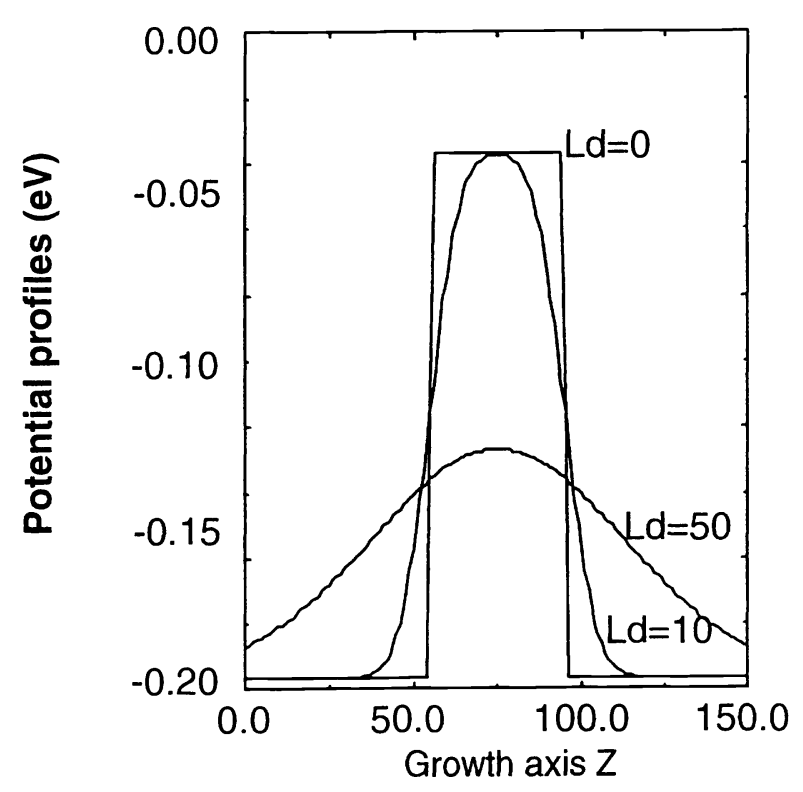

Fig. 6 The potential profile of $\mathrm{In}_{0.09} \mathrm{Ga}_{0.81} \mathrm{~N} / \mathrm{GaN}$ with $\mathrm{L}_{\mathrm{w}}=80 \AA$ and $\mathrm{L}_{\mathrm{d}}=0$

In Fig. 3, the potential profile of $\mathrm{HH}, \mathrm{LH}$ and $\mathrm{CH}$ for $\mathrm{L}_{\mathrm{w}}=50 \AA$ are shown. It was found that for as-grown well $\mathrm{L}_{\mathrm{d}}=0 \AA$, the potential profiles are similar to $\mathrm{SQW}$. For $\mathrm{L}_{\mathrm{d}}=10$ and $50 \AA$, the potential profiles are determined by error function and the distribution of In mole fraction is also determined by error function with maximum In mole fraction in the middle of the well. For $L_{d}=50 \AA$ may be due to larger diffusion coefficient or diffusion time or both. This contributes to a potential well for the confinement of carrier to increase the efficiency of radiation. For InN, it is more soft compared with AlN, it is possible to achieve interdiffusion of In atoms. The increase in the In mole fraction, the deeper will be the potential profiles. With the increase of diffusion length of $\operatorname{InGaN} / \mathrm{GaN} Q W$ for $\mathrm{L}_{\mathrm{w}}=50 \AA$ from $\mathrm{L}_{\mathrm{d}}=0 \AA$ through $10 \AA$ to $50 \AA$ as shown in Fig. 1, Fig. 4 and 5 with same subband structure order as Fig. 1, we found that the energy dispersion of valence subbands shifts downward with increase in diffusion length and smooth out. In $\mathrm{L}_{\mathrm{d}}=0 \AA$ and $10 \AA$, they have similar valence subbands dispersion and more parabolic in shape. Besides, the coupling between LH1 and HH2 still exists but weakens a little bit at region $k_{t}$ greater than $0.04 \AA$ and the coupling between $H H 2$ and $L H 2$ diminished significantly. For $L_{d}=50 \AA$, the energy dispersion of valence subbands approaches the bulk band structure and more parabolic in shape and shifts further downwards. The coupling between LH1 and $\mathrm{HH} 2$ at around zone centre and a weak coupling between $\mathrm{HH} 2$ and LH2 at around $\mathrm{k}_{\mathrm{t}}=0.03 \AA^{-1}$ and strong coupling between $\mathrm{CH} 1$ and $\mathrm{HH} 3$ at around $\mathrm{k}_{\mathrm{t}}=0.04 \AA^{-1}$.

For as-grown well with $L_{w}=80 \AA$ and $x=0.09$, the potential profile of $H H, L H$ and $C H$ are similar to that with $\mathrm{L}_{\mathrm{w}}=50 \AA$ and was shown on Fig. 6. From Fig. 2, it was found that there is a strong coupling of LH1 and HH2 at zone centre and coupling of $\mathrm{HH} 2$ and $\mathrm{LH} 2$ in region where $\mathrm{k}_{\mathrm{t}}$ greater than $0.03 \AA^{-1}$. It was also found that HH1 was quite parabolic in shape. Besides, higher order subbands and subbands in regions where $k_{t}$ is large enough are parabolic in shape. With the increase of diffusion length of InGaN/GaN QW for $L_{w}=80 \AA$ from $L_{d}=0 \AA$ through $10 \AA$ to $50 \AA$ as shown in Fig. 2 , Fig. 7 and 8 with same subband structure order as Fig. 2, we found that the energy dispersion of valence subbands shifts downward with increase in diffusion length and smooth out. In $L_{d}=0 \AA$ and $10 \AA$, they have similar valence subbands dispersion and more parabolic in shape. Besides, the coupling between LH1 and HH2 still exists but weakens a little bit at region $\mathrm{k}_{\mathrm{t}}$ greater than $0.03 \AA^{-1}$ and the coupling between $\mathrm{HH} 2$ and $\mathrm{LH} 2$ at region where $\mathrm{k}_{\mathrm{t}}$ greater than $0.04 \AA^{-1}$. For $\mathrm{L}_{\mathrm{d}}=50 \AA$, the energy dispersion of valence subbands approaches the bulk band structure and more parabolic in shape and shifts further downwards. The coupling between LH1 and HH2 weaken at around zone centre and coupling between $\mathrm{HH} 2$ and $\mathrm{LH} 2$ at around $\mathrm{k}_{\mathrm{t}}=0.035 \AA^{-1}$ and strong coupling between $\mathrm{CH} 1$ and $\mathrm{HH} 3$ at around $\mathrm{k}_{\mathrm{t}}=0.04 \AA^{-1}$. 


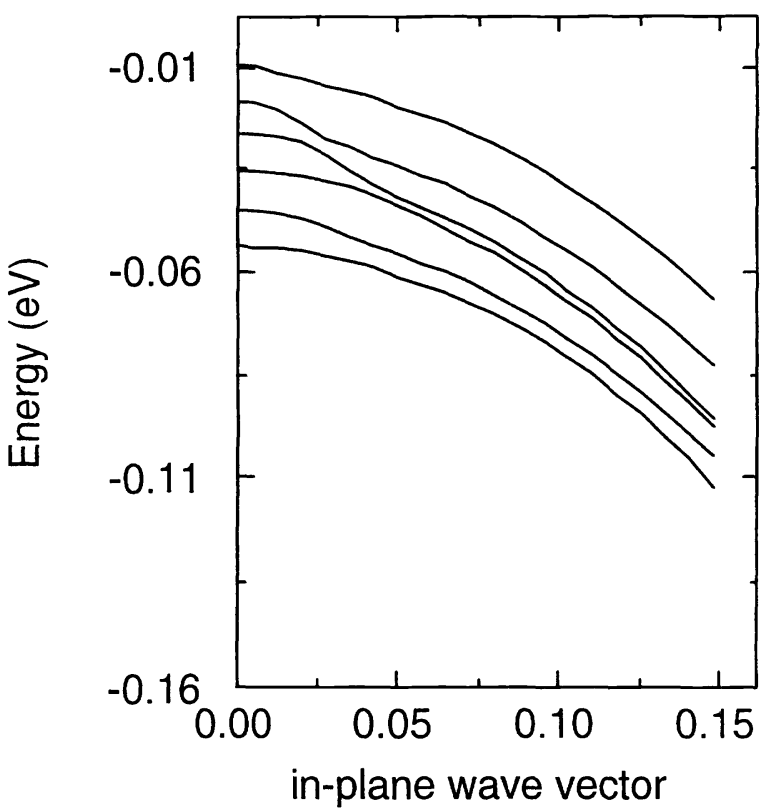

Fig. 7 The valence band structure of $\operatorname{In}_{0.09} \mathrm{Ga}_{0.91} \mathrm{~N} / \mathrm{GaN}$ with $\mathrm{L}_{\mathrm{w}}=80 \AA$ and $\mathrm{L}_{\mathrm{d}}=10 \AA$.

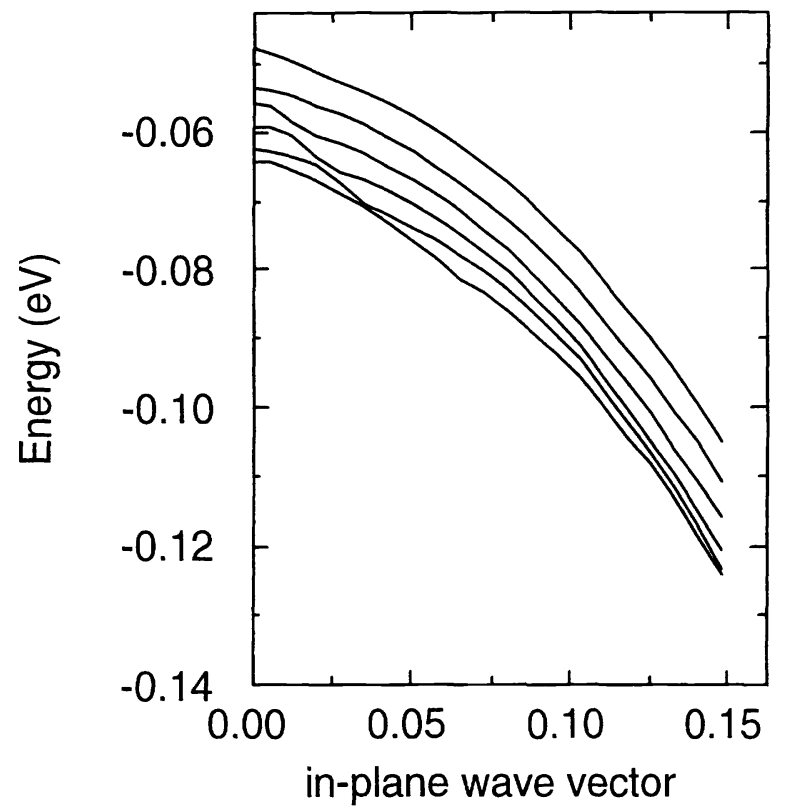

Fig. 8 The valence band structure of $\operatorname{In}_{0.09} \mathrm{Ga}_{0.91} \mathrm{~N} / \mathrm{GaN}$ with $\mathrm{L}_{\mathrm{w}}=80 \AA$ and $\mathrm{L}_{\mathrm{d}}=50 \AA$.

\section{CONCLUSIONS}

We have presented a detailed study of the interdiffusion electronic band structures of WZ-InGaN/GaN and compared with SQW. Our calculation is based on the effective mass Hamiltonian derived using the k.p method by finite difference method. As interdiffusion proceeds, the valence band dispersion approaches parabolic in shape with similar band structure with small diffusion length but large difference with large diffusion length, which is due to the modification of the well shape, i.e., depth and width, in terms of a crossover point. A depth-dependent well width is discussed and a cutoff scheme is introduced to distinguish between the bound and unbound states. The envelope wave functions were found to be more spread out with the probability away from the well centre increasing as $L_{d}$ increases

\section{ACKNOWLEDGMENTS}

This work is supported by the RGC earmarked grant of Hong Kong and the University of Hong Kong CRCG grant for financial support.

\section{REFERENCES}

1. S. Nakamura, "InGaN-baesd blue laser diodes", IEEE J. Selected Topics Quantum Electron., vol. 3, pp.712-718, 1997.

2. S. Nakamura, M. Senoh, N. Iwasa, S. Nagahama, T. Yamada, and T. Matsushita, "Superbright green InGaN singlequantum-well-structure light-emitting-diodes", Jpn. J. Appl. Phys. Lett., vol. 34, pp.L1332-1335, 1995. 
3. S. Nakamura, M. Senoh, S. Nagahama, N. Iwasa, T. Yamada, T. Matsushita, H. Kiyoku, and Y. Sugimoto, "InGaNbased multi-quantum-well-structure laser diodes", Jpn. J. Appl. Phys., vol.35, pp. L74-76, 1996.

4. S. L. Chuang and C. S. Chang, "A band-structure model of strained quantum-well wurtzite semiconductors", Semicond. Sci. Technol., vol.12, pp. 252-263, 1997.

5. S. Yuan, Y. Kim, C. Jagadish, P. T. Burke, M. Gal, J. Zou, D. Q. Cai, D. J. H. Cockayne, and R. M. Cohen, "Novel impurity-free interdiffusion in GaAs/AlGaAs quantum-wells by anodization and rapid thermal annealing", Appl. Phys. Lett., vol. 70, pp. 1269-1271, 1997.

6. S. Burkner, M. Maier, E. C. Larkins, W. Rothemound, E. P. O'Reilly, and J. D. Ralston, "Process parameter dependence of impurity free interdiffusion in $\mathrm{GaAs} / \mathrm{Al}_{\mathrm{x}} \mathrm{Ga}_{1-\mathrm{x}} \mathrm{As}$ and $\mathrm{In}_{\mathrm{y}} \mathrm{Ga}_{1-\mathrm{y}} \mathrm{As} / \mathrm{GaAs}$ multiple quantum wells, $\mathrm{J}$. Electronic Materials, vol. 24, pp. 805-812, 1995.

7. I. Gontijo, T. Krauss, J. H. Marsh, and R. M. De La Rue, "Postgrowth control of GaAs/AlGaAs quantum well shapes by impurity-free vancancy diffusion", IEEE J. Quantum Electron., vol. 30, pp. 1189-1194, 1994.

8. C. K. Sun, S. Keller, T. L. Chiu, G. Wang, M. S. Minsky, J. E. Bowers, S. P. DenBaars, "Well-width dependent studies of InGaN-GaN single-quantum wells using time-resolved photoluminescence technique", IEEE J. Selected Topics Quantum Electron., vol. 3, pp. 731, 1997.

9. W. D. Herzog, R. Singh, T. D. Moustakas, B. B. Goldberg, M. S. Unlu, "Photoluminescence microscopy of InGaN quantum wells", Appl. Phys. Lett., 70, pp. 1333-1335, 1997. 